\title{
Vigie-flore - a nationwide monitoring programme for common plant species and plant communities in France
}

\author{
Nathalie Machon, Emmanuelle Porcher \& Daniel Mathieu
}

\begin{abstract}
Vigie-flore (http://www.vigie-flore.fr; GIVD ID EU-FR-001) is a nation-wide plant monitoring programme aiming to detect temporal trends in the abundance of common plant species in France. This monitoring program is part of the more general biodiversity monitoring programme Vigie-nature (www2.mnhn.fr/vigie-nature/) steered by the French Musée National d'Histoire Naturelle. Similarly to other Vigie-nature sections, Vigie-flore is a citizen science program that is based on the involvement of volunteer expert botanists. The programme is jointly steered by the "Conservation des Espèces, Restauration et Suivi des Populations" lab (http://www2.mnhn.fr/cersp/) and by Tela Botanica (http://www.tela-botanica.org), the network of French speaking botanists. Vigieflore uses a two-stage standardized sampling scheme. More than 5,500 $1 \mathrm{~km}^{2}$ squares are systematically distributed throughout France, following a regular grid with $10 \mathrm{~km}$ between each square. This systematic distribution of monitoring sites provides an accurate and representative picture of the different habitat types. When a volunteer enrols, a convenient (=closely located) square is assigned to him/her. Within each $1 \mathrm{~km}^{2}$ square, eight permanent plots are evenly distributed together with eight replacement plots in case the former are not accessible. The volunteers are asked to monitor as many permanent plots as possible within a square (up to eight), but data on single permanent plots are nonetheless accepted. The permanent plots are rectangular areas of $10 \mathrm{~m}^{2}$ that are subdivided into 10 $1 \mathrm{~m}^{2}$ squares in which the volunteers record all vascular plants once a year, in spring. The abundance of each species can be measured as the frequency of occurrence across the $101 \mathrm{~m}^{2}$ squares. Vigie-flore was launched in spring 2009 and involves, as of January 2012 , 120 volunteers monitoring plant communities in $1651 \mathrm{~km}^{2}$ squares. So far, this yielded data for a total of around 1,800 species. Such data are currently used to examine spatial patterns in plant community composition. These patterns are related to environmental variables (e.g. habitat type, habitat fragmentation) to identify some of the drivers of plant community composition. In the long term, the aim is to analyse temporal trends in plant community composition, to identify underlying mechanisms and also to understand ecological consequences using trait-based approaches.
\end{abstract}

Keywords: citizen-science; plant species abundance.

\section{Vigie-flore}

Scope: Vigie-flore is a French plant monitoring program to detect spatial and temporal trends in the abundance of common plant species, as well as changes in plant community composition, and identify underlying drivers. It is based on systematic sampling of survey sites and on a standardized protocol to record species presence and abundance, and involves volunteer botanists.

Status: ongoing capture

Period: 2009-2011

Database manager(s): Nathalie Machon (machon@mnhn.fr); Emmanuelle Porcher (porcher@mnhn.fr); Daniel Mathieu (dmathieu@telabotanica.org)

Owner: Each volunteer owns their own data

Web address: $h$ ttp://www.vigie-flore.fr

Availability: according to a specific agreement

Database format(s): MySQL

Online upload: no

Online search: no

Publication: [NA]

Plot type(s): nested plots; time series

Non-overlapping plots: 165

Total plot observations: 1,111

Export format(s): Excel, CSV file

Countries: FR: $100.0 \%$

Forest: [NA] - Non-forest: [NA]

Guilds: all vascular plants: $100 \%$

Environmental data: altitude: $100 \%$; slope aspect: $100 \%$; slope inclination: $100 \%$

Performance measure(s): presence/absence only: $100 \%$; cover: $100 \%$

Geographic localisation: GPS coordinates (precision $25 \mathrm{~m}$ or less): $100 \%$

Sampling periods: $2000-2009: 30.0 \%$; $2010-2019: 70.0 \%$

Information as of 2012-07-12; further details and future updates available from http://www.givd.info/ID/EU-FR-001 
Nathalie Machon (machon@mnhn.fr), Emmanuelle Porcher* (porcher@mnhn.fr)

Conservation des Espèces, Restauration et Suivi des Populations, Muséum national d'Histoire naturelle, 55 rue Buffon, 75005 Paris, FRANCE

Daniel Mathieu (dmathieu@ tela-botanica.org)

Tela Botanica, Institut de Botanique, 163 Rue Auguste Broussonnet, 34090 Montpellier, FRANCE

*Corresponding author 